- Washington in Seattle wondered what a blood-boosting hormone was doing in the brain. In subsequent animal studies, she found that the hormone stopped brain cells from dying and helped the brain to repair itself ${ }^{3}$. That led a few years later to the first clinical trials showing that EPO prevents brain damage in babies.

\section{MOVING ON}

In June, a study conducted by Juul and her colleagues reported the results of giving EPO or a placebo, along with inducing hypothermia, just after birth to dozens of babies at risk of brain injury. Those who received EPO were less likely than those given the placebo to show signs of brain damage on magnetic resonance imaging tests done five days later ${ }^{4}$.

Those results led to the forthcoming clinical study. Co-led by Juul and Yvonne $\mathrm{Wu}$, a paediatric neurologist at the University of California, San Francisco, the trial will enrol 500 babies at risk of brain injury from 17 hospitals across the United States during their first 24 hours of life.

All the babies will be treated with hypothermia. Half will then receive five doses of EPO over seven days; the other half will get saline injections. The US\$10-million trial will measure whether the hormone boosts the children's mental and physical health at 2 years of age.

Researchers are also testing EPO in babies born as early as 23 weeks in the United States and Europe. Such premature babies are more likely to develop brain injury than are full-term babies, and smaller studies have produced conflicting results about the benefits of EPO in these very early cases.

But neonatologist Giancarlo Natalucci of the University of Zurich, who was part of a Swiss trial that found EPO didn't improve the health of two-year-olds who had been treated as premature babies ${ }^{5}$, says that factors such as dose may account for such results. He still thinks that the treatment merits study.

The trials are difficult to conduct because it's hard to tell whether a symptom is a side effect of treatment or the result of a baby's underlying injuries.

But despite the hurdles, Juul and other researchers press on, driven by their desire to aid the world's smallest patients. "They're in such desperate need of help," Juul says. .

1. Azzopardi, D. et al. N. Engl. J. Med. 371, 140-149 (2014).

2. Masuda, S. et al. J. Biol. Chem. 268, 1120811216 (1993).

3. Kellert, B. A., McPherson, R. J. \& Juul, S. E. Pediatric Res. 61, 451-455 (2007).

4. Wu, Y. W. et al. Pediatrics 137, e20160191 (2016).

5. Natalucci, G. et al. J. Am. Med. Assoc. 315, 2079-2085 (2016).

\title{
Speedy drills start hunt for oldest ice
}

\section{British team first to seek site of 1.5-million-year-old sample.}

\section{BY QUIRIN SCHIERMEIER}

A s the short Antarctic spring ends and long summer days approach, geoscientists are flocking to the frozen continent to start a new kind of exploration.

In December, the first drill designed to search for a scientifically useful sample of ice that is at least 1.5 million years old will begin its work. It is part of a broader effort to locate the best place to extract a core containing Earth's oldest ice, which would help to reveal how climate has shaped the planet's past and how to predict future fluctuations.

"This exciting field season should bring us a large step nearer to deciding where to drill the oldest-ice core," says Olaf Eisen, a glaciologist at the Alfred Wegener Institute of Polar and Marine Research in Bremerhaven, Germany, who coordinates an exploration team funded by the European Union.

More than a decade ago, the European Project for Ice Coring in Antarctica (EPICA) drilled the oldest existing core, which contains 800,000-year-old ice, from an ice dome in East Antarctica known as Dome C. The core reaches only as far back as the latter part of the Pleistocene epoch, when Earth began cycling between warm and cold periods every 100,000 years.
Before 1 million years ago, the cycle occurred every 40,000 years (L. E. Lisiecki and M. E. Raymo Paleoceanography 20, PA1003; 2005), so scientists want an ice core that is twice as old as EPICA to better understand this transition.

Digging such a core would cost about US\$50 million and take several years, so researchers want to be sure that the location is optimal - with ice that is sufficiently deep but not melted at the bottom by geothermal activity. "It's absolutely crucial to thoroughly investigate all options," says Eisen. Enter a new breed of drill, designed to do fast, cheap reconnaissance instead of extracting a single, intact ice core, as previous deep drills have done.

One promising location, 'little Dome C', lies just 40 kilometres away from the EPICA site - and is where the $£ 500,000$ (US $\$ 620,000$ ) Rapid Access Isotope Drill (RAID) will start boring this month, led by climate scientist Robert Mulvaney of the British Antarctic Survey in Cambridge, UK. A narrow drill, RAID will excavate to 600 metres in about 7 days - compared with 5 years for a 3.4-kilometre core such as EPICA's. And rather than extract a core, RAID will measure the ice's temperature and collect chips of ice. Scientists will then comb these for clues from isotopes as to the age and temperature of the ice at the bottom of the sheet.

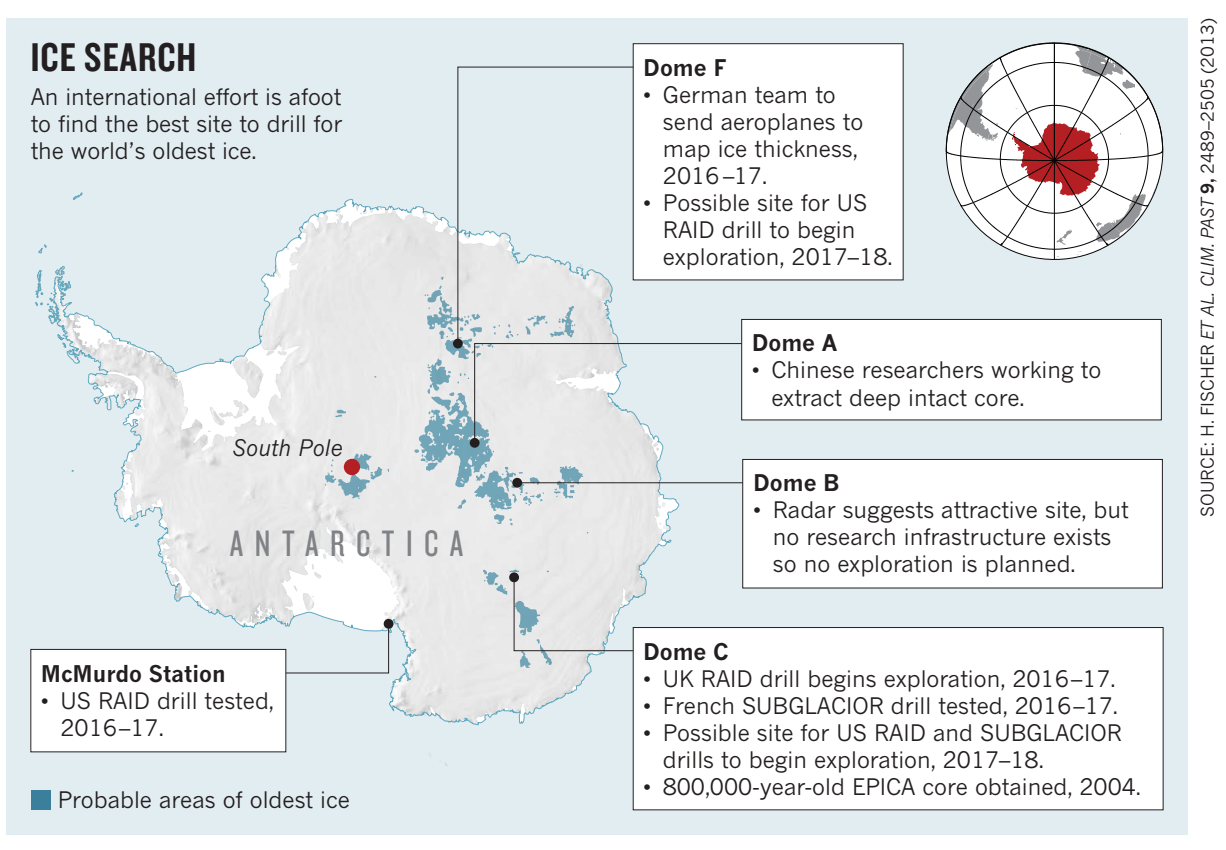


A more expensive reconnaissance instrument, which will do its first drilling tests this season at Dome C, should be ready to take a deeper look next year. Led by glaciologist Jérôme Chappellaz of Joseph Fourier University in Grenoble, France, the $€ 3$.2-million (US\$3.4-million) SUBGLACIOR probe, which is about the same width as RAID, can penetrate the more than 3-kilometre-thick ice sheet in a single season.

Both the UK and French drilling projects are funded as part of the EU collaboration. But also this season, a US team led by climatologist Jeffrey Severinghaus of the Scripps Institution of Oceanography in La Jolla, California, and John Goodge of the University of Minnesota, Duluth, will test the \$10.5-million Rapid Access Ice Drill (also abbreviated RAID) at Minna Bluff, near the US McMurdo Station on Ross Island. Producing a hole of about 8 centimetres - similar to the boreholes of the other drills - it is the only rapid drill that can extract rocks from the bottom of a core. Next Antarctic summer, the

team will begin its hunt for the site of a 1.5-million-year-old core.

Dome $\mathrm{C}$ is one option for its first excavation. Another is the relatively unexplored Dome F in Antarctica's Queen Maud Land, which ground-based radar suggests is a promising candidate (see 'Ice search'). In January, a German team will run reconnaissance flights

\section{"You cannot}

trust a single core." there. Funded by the same European grant as the UK RAID and SUBGLACIOR drills, this radar survey will give a more comprehensive view of the ice thickness. Severinghaus says that his team will watch for the data when deciding where to point the US RAID.

Both the US and European teams are working under an umbrella group. The International Partnerships in Ice Core Sciences (IPICS) aims to identify a suitable site to drill a core representing Antarctica's oldest ice in the next two years. That drilling could start by the end of 2020, says Eisen. But how the international teams would work together on a joint project, or share funding, is unclear.

There's a possibility that a record-breaking ancient core could show up sooner. For several years, scientists at the Polar Research Institute of China in Shanghai, who are also members of IPICS, have been probing the ice sheet that covers Dome A, a plateau close to the centre of the Antarctic continent. Using a conventional corer rather than a rapid exploratory drill, they are working on obtaining a deep, intact ice core from the region, says Eisen - and it is possible that it could stretch back to 1.5 million years. Such a surprise success would increase pressure on teams from other nations to produce their own record, he says.

Multiple cores would benefit science. "We would carry on with our project," says Eisen. The IPICS effort would ideally excavate multiple 1.5-million-year-old cores in any case. "You cannot trust a single core," says Severinghaus. "We absolutely need different records from different thermal regimes." -

\section{Weaponized antibodies use new tricks to fight cancer}

\section{Next generation of Trojan-horse drugs designed to minimize damage to healthy cells.}

\section{BY HEIDI LEDFORD}

$\mathrm{A}$ fter decades of frustration, efforts to develop antibodies that can ferry drugs into cancer cells - and minimize damage to healthy tissue - are gathering steam. The next generation of these 'weaponized antibody' therapies, called antibody-drug conjugates (ADCs), is working its way through clinical trials.

Researchers will gather to discuss this renaissance on 30 November at the Symposium on Molecular Targets and Cancer Therapeutics in Munich, Germany. The improvements come after the first wave of experimental ADCs failed to deliver on its promise.

"Initially there was a lot of excitement, and then slowly many of them did not work," says Raffit Hassan, a cancer researcher at the US National Cancer Institute in Bethesda, Maryland. Now, he says, there are two new ADCs in phase III clinical trials, and many more in earlier-stage testing.

The concept that underlies these drugs is simple: repurposing an antibody as a vehicle to deliver a toxic drug into a cancer cell. When the antibody in an ADC seeks out and docks

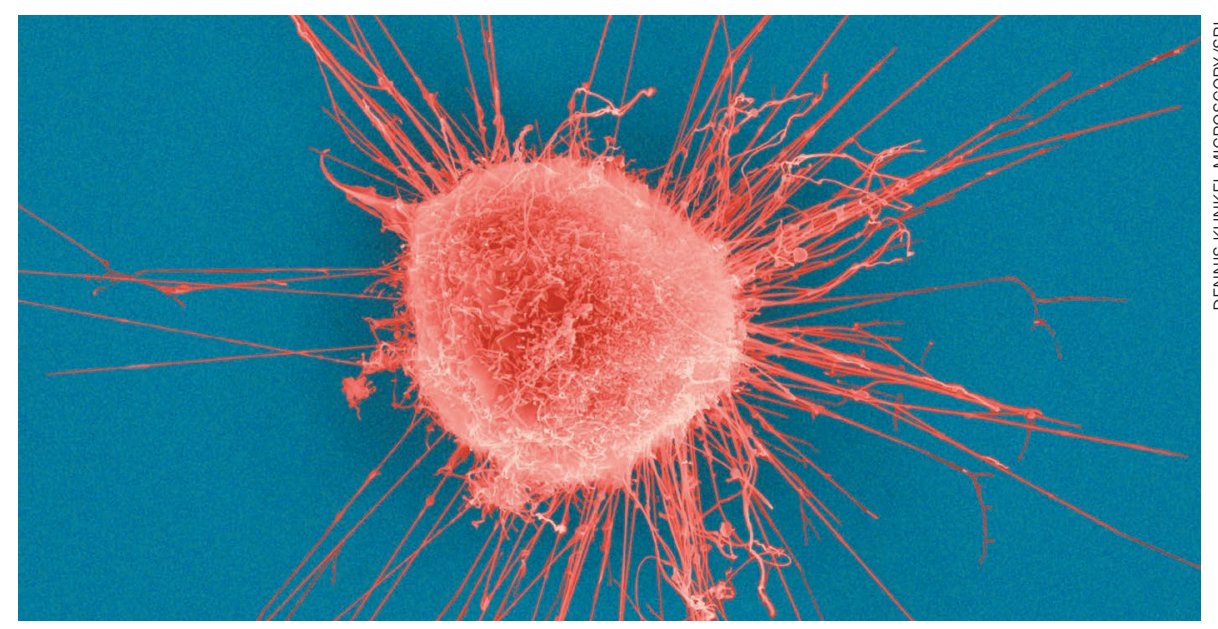

Breast-cancer cells might be susceptible to drugs that masquerade as antibodies to sidestep defences.

onto a tumour cell, the cell takes it up and cleaves the molecular links that bind the drug to the antibody. This frees the drug to kill the cell from within.

But this approach has proved tricky to realize. Sometimes the molecular linkers are too tight, and do not release the drug inside the cell. Sometimes they are too unstable, and release the drug near healthy cells - limiting the dose that can be administered. Even the drugs themselves can be problematic: because most are toxic mainly to rapidly dividing cells, they can leave behind the slowly dividing cells that seed some tumours. And some have had trouble penetrating more than a few cell layers into their target tumours.

Researchers have been chasing ADCs for decades, Hassan says. The US Food and 


\section{NEWS INFOCUS}

\section{CORRECTION}

In the story 'Speedy drills start hunt for oldest ice' (Nature 540, 18-19; 2016), the size of the borehole to be drilled by the US RAID was wrong. It will be about $8 \mathrm{~cm}$, and so roughly the same size as the other planned holes. The story should also have noted that as well as Jeffrey Severinghaus, the US project is co-led by John Goodge of the University of Minnesota, Duluth. 